\title{
Green Stimulus in a Post-pandemic Recovery: the Role of Skills for a Resilient Recovery
}

\author{
Ziqiao Chen $^{1} \cdot$ Giovanni Marin ${ }^{2,3} \cdot$ David Popp $^{1,4}$ (D) $\cdot$ Francesco Vona ${ }^{5,6,7}$
}

Accepted: 9 July 2020 / Published online: 4 August 2020

(c) Springer Nature B.V. 2020

\begin{abstract}
As nations struggle to restart their economy after COVID-19 lockdowns, calls to include green investments in a pandemic-related stimulus are growing. Yet little research provides evidence of the effectiveness of a green stimulus. We begin by summarizing recent research on the effectiveness of the green portion of the 2009 American Recovery and Reinvestment Act on employment growth. Green investments are most effective in communities whose workers have the appropriate "green" skills. We then provide new evidence on the skills requirements of both green and brown occupations, as well as from occupations at risk of job losses due to COVID-19, to illustrate which workers are most likely to benefit from a pandemic-related green stimulus. We find similarities between some energy sector workers and green jobs, but a poor match between green jobs and occupations at risk due to COVID-19. Finally, we provide suggestive evidence on the potential for job training programs to help ease the transition to a green economy.
\end{abstract}

Keywords Green subsides - Green stimulus - American Recovery and Reinvestment Act · Heterogeneous effect · Distributional impacts

JEL Classification E24 $\cdot$ E62 $\cdot \mathrm{H} 54 \cdot \mathrm{H} 72 \cdot \mathrm{Q} 58$

David Popp

dcpopp@maxwell.syr.edu

1 Syracuse University, New York, USA

2 University of Urbino Carlo Bo, Urbino, Italy

3 SEEDS, Urbino, Italy

4 NBER, Cambridge, USA

5 OFCE Sciences-Po, Paris, France

6 SKEMA Business School, Université Côte d'Azur, Valbonne, France

7 CMCC, Ca' Foscari, Venice, Italy 


\section{Introduction}

Nations around the world have shut down large portions of their economy in response to the COVID-19 pandemic. Government spending will be important to both maintain the economy during these shutdowns and to help restart the economy as restrictions are lifted. Among the many proposals for pandemic-related stimuli include calls for a "green" stimulus that both restarts the economy and helps it transition to a cleaner, more sustainable path (e.g. Helm 2020, Agrawala et al. 2020). ${ }^{1}$ Notably, the new European Commission puts the green fiscal stimulus at the center of its growth strategy to achieve social, economic, and environmental goals. The European Green Deal (EGD henceforth) is "a new growth strategy that aims to transform the EU into a fair and prosperous society, with a modern, resource-efficient and competitive economy where there are no net emissions of greenhouse gases in 2050 and where economic growth is decoupled from resource use" (European Commission 2019, p. 2). Funding for the EGD will be expanded in the context of the COVID-19 plans within the Recovery Plan for Europe (Next Generation EU, €750 billion for 2021-2014) and the reinforced long-term EU budget ( $€ 1.1$ trillion for 2021-2027), approved on May 27th, 2020, with 25\% of the funding allocated towards climate-friendly expenditures. Similar proposals have been made by the head of the International Monetary Fund and the International Energy Agency. ${ }^{2}$

The only effort of a similar scale for the green economy has been mobilized by the 2009 United States stimulus in response to the Great Recession, formally known as the American Recovery and Reinvestment Act, or ARRA, which set aside funds for "... environmental protection, and infrastructure that will provide long-term economic benefits" (American Recovery and Reinvestment Act of 2009). In a recent working paper (Popp et al. 2020), we use the US experience to estimate the effectiveness of such spending on job creation in the aftermath of the 2009 crisis. There, the issue of skill availability is crucial for the success of green stimuli. We find that areas whose labor force was already endowed with the relevant green skills benefit the most in terms of job creation. In this note, we discuss the policy implications of this research for any future green investments as part of a pandemicrelated stimulus while providing new evidence on (1) the skills required for in-demand green jobs, brown jobs likely to be at risk in a green economy, and other jobs at risk due to COVID-19; and (2) the potential of investments in training for the skills required to operate green technologies.

\section{Background}

The US American Recovery and Reinvestment Act (ARRA) of 2009, commonly known as the stimulus package, invested over $\$ 800$ billion stimulate the US economy. ARRA included several programs designed to promote clean energy and green jobs (Aldy 2013).

\footnotetext{
${ }^{1}$ Here, and throughout the paper, we use "pandemic-related stimuli" to refer to both stimulus packages designed to see the economy through a lockdown, and later investments designed to pull the economy out of recessions resulting from the pandemic.

${ }^{2}$ https://www.climatechangenews.com/2020/04/29/imf-chief-1-trillion-post-coronavirus-stimulus-musttackle-climate-crisis/, last accessed June 24, 2020, and https://www.iea.org/news/iea-and-denmark-hostministerial-roundtable-discussion-on-making-clean-energy-a-key-part-of-the-global-economic-recovery, last accessed June 24, 2020.
} 
These include both direct spending intended for immediate job creation, such as Department of Energy (DOE) spending for renewable energy and energy efficiency retrofits and Environmental Protection Agency (EPA) grants for brownfield redevelopment, as well as tax breaks and loan guarantees for renewable energy.

In Popp et al. (2020), we estimate the impact of direct spending programs managed by the DOE and EPA, all of which are plausibly green. Combining project data from FederalReporting.gov with employment and economic data from local communities, we estimate the employment effects of green ARRA investments. As in most recent evaluations of other types of ARRA spending (e.g. Dupor and Mehkari 2016; Dupor and McCrory 2018), our unit of analysis is a commuting zone, which represents the local labor market. Overall, the stimulus included over $\$ 61$ billion of direct spending on green investments and \$265.5 billion on non-green investments. The mean value of green ARRA and non-green ARRA per commuting zone in our sample are $\$ 103$ million and $\$ 442$ million dollars, respectively. Thus, just under $20 \%$ of ARRA funded green investments, slightly less than the $25 \%$ currently proposed by the European Union. However, while the proposed European Green Deal is larger than the green ARRA stimulus, the definition of the plan and its composition between guaranteed loans and direct spending is unclear so far. ${ }^{3}$

\section{Discussion of the Key Results}

Our first key finding is that green stimulus investments increased total employment, but that they worked more slowly than other stimulus investments. In our preferred specification in Popp et al. (2020), we estimate that each \$1 million of green ARRA investments created just under 15 jobs, or roughly $\$ 67,750$ per job, in the post-ARRA period (2013-2017). While the persistency of the job creation effect is clearly a positive aspect of the green fiscal stimulus, we find little evidence of short-run employment gains. Although the magnitude of jobs created is similar to what studies of other types of ARRA investments find, studies of other stimulus investments, such as construction and highway infrastructure, typically find evidence of short-run job creation (e.g. Wilson 2012; Garin 2019; Chodorow-Reich 2019).

Second, the impacts of a green stimulus on employment are heterogeneous. Not surprisingly, we find a large effect on green job creation, measured using the task approach proposed by Vona et al. (2018). Because nearly half of the jobs created by green ARRA investments were in construction or waste management, nearly all of the employment gains are in manual labor occupations. The employment gains are greatest for those manual laborers with more than a high school degree. Interestingly, however, these new jobs are not necessarily well-paying jobs, as the largest gains in employment for manual workers are in occupations with an hourly wage below the US median for manual workers. Workers specialized in manual tasks are gaining new jobs, but not necessarily well-paying jobs.

Third, and most important for this note, our research also illuminates where green stimulus investments work. In Vona et al. (2018), we use data from the U.S. Department of Labor's O*NET database to identify the skills demanded in occupations expected to be

\footnotetext{
3 At the time we are writing this article, it is not yet clear which share of the EU stimulus will be constituted by subsidies and which by guaranteed loans and other financial instruments. See, for instance, https ://www.europarl.europa.eu/RegData/etudes/BRIE/2020/649371/EPRS_BRI(2020)649371_EN.pdf, last accessed June 27, 2020.
} 
prominent in a green economy. For each occupation, the O*NET database provides the tasks expected to be performed by workers in their occupation and the skills needed to complete these tasks. Tasks are further divided into 'general' tasks, which are common to all occupations, and 'specific' tasks that are unique to individual occupations. Using O*NET data on the importance of general skills to each occupation, Vona et al. (2018) identify Green General Skills. Such skills are potentially used in all occupations, but are in higher demand in jobs relevant for a green economy. These skills include engineering, operations management, monitoring, and science skills. While such skills are mostly associated with college graduates, the engineering skills required by a green economy also include building and construction skills. ${ }^{4}$

We find that the effectiveness of green stimulus spending varies depending on the prevalence of jobs using green skills in a community prior to the Great Recession. The long-run benefits of the green stimulus were highest in those communities with more green skills. Moreover, the green stimulus was ineffective in areas with less than the median penetration of occupations emphasizing green skills: statistically significant positive employment gains occur in communities in the $46^{\text {th }}$ percentile and higher of green skills penetration.

This result is consistent with findings in labor economics (e.g., Kambourov and Manovskii 2009; Gathmann and Schönberg 2010) where the cost of job reallocation (in this case induced by environmental policy) is proportional to the skill distance between jobs. Thus, the larger the distance between skills required by green jobs created and brown jobs lost in a green economy, the more costly the transition to green economy will be. The issue is relevant both theoretically, to calibrate general equilibrium model that explicitly incorporate costly job reallocation (Hafstead and Williams 2018), and politically, for the political acceptability of green fiscal policy in front of the emerging populistic platforms that deny climate change or over-emphasize the "job killing" argument (Vona 2019). As the Yellow Vest movement has shown, the green stimulus will remain an empty box without the political support of those left behind. Workers displaced from brown jobs will find green policies less acceptable if their skill endowments, i.e. their main asset, is completely destroyed by such policy. Not by chance, an important fraction of the proposed European Green Deal is devoted to upskilling the work force as well to a Just Transition fund to ensure that no country and worker is left behind. ${ }^{5}$ We provide evidence on the workers most likely to benefit from green investments in our discussion of policy implications below.

\section{Policy Implications}

Our findings in Popp et al. (2020) provide guidance as to how green investments can be used effectively as part of a pandemic-related stimulus package. While a green stimulus can help reshape the economy, it is less likely to help restart the economy. To put limited government funds to the best use, the majority of a pandemic-related stimulus should initially focus on investments that get people back to work quickly. Green investments appear less likely to help with this task.

\footnotetext{
4 See Vona et al. (2018) for details and descriptive statistics on green skill constructs.

5 "The Just Transition Mechanism will focus on the regions and sectors that are most affected by the transition because they depend on fossil fuels or carbon-intensive processes. [...] It will also strive to protect the citizens and workers most vulnerable to the transition, providing access to re-skilling programmes, jobs in new economic sectors, or energy-efficient housing" (European Commission 2019, p. 1).
} 
That does not mean there is no role for green investments in a pandemic-related stimulus. The long run benefits of a green stimulus are real. The investments put forward in response to the pandemic must be designed for the world to come, which includes the need to respond to the climate crisis. Investments in infrastructure, for example, could consider future demand for public transportation and electric vehicle charging stations. But it is important to understand who benefits from these investments. Green stimulus investments will be most effective in communities where workers have the skills needed for a green economy. To highlight which types of workers may benefit, Table 1 provides information on several dimensions of skills and training requirements for specific green and brown manual occupations: education, experience, training requirements, and the importance of general green skills. For green skills we include the average of the four green skill groups in Vona et al. (2018), as well as the importance of green engineering and technical skills, which are most relevant for these manual workers. To coincide with the finding that a green stimulus is most effective in communities with a high presence of jobs in the upper quartile of green skills importance, we report the quartile for each green skill, as well as the average value for each group of occupations. High-demand and low-demand green and brown occupations are those green and brown occupations with the highest and lowest projected percentage growth rate in employment for 2018-2028 in the BLS Employment Projections database. We note, however, that high-demand brown jobs include several positions in the oil and gas industry that have since become vulnerable due to falling oil prices, and that would be in lower demand should a true transition to a green economy begin.

We also include information on 10 manual occupations at risk due to COVID-19 and social distancing requirements, based on Mongey et al. (2020). Mongey et al. (2020) develop occupation-specific measures for the ease of working at home and physical proximity to other people in the workplace. Montenovo et al. (2020) use these measures to show that job losses from COVID-19 are greatest in jobs with low work from home potential and high proximity in the workplace. Our at-risk occupations all have a low capacity of working at home and a high physical proximity measure $(>0.75)$. From all such occupations, we identified the 10 occupations with the highest employment levels in the 2-digit occupation classes 35 (food prep and serving), 39 (personal care and service) or 53 (transportation), excluding those personal care workers involved in health care. Helping workers in jobs such as these will likely be a high priority for a pandemic-related stimulus.

Most notably, the data suggest a green stimulus can be effective for workers in previously high-demand brown occupations such as the oil and gas industry, whose demand increased substantially thanks to the fracking boom. Workers in this industry have been hit hard by falling oil and gas prices. Most of these occupations are in the third or fourth quartile of overall green skills importance, and 9 of the 10 are in the top quartile for green engineering and technical skills. The average importance measure for these jobs is quite similar to the average measure for the top green jobs. Both high-demand green and brown jobs require similar levels of related work experience. Because green jobs require over a year of on-the-job training, some training will likely be required for workers transitioning from high-demand brown to green jobs. However, the similar skill set for these workers provides hope that training will be successful. We elaborate on the potential of job training to complement green subsidies below.

Green stimulus investments are less likely to help brown workers in low-demand jobs, which are primarily manufacturing positions. These jobs make less use of the general skills used in green jobs and also have significantly lower training and experience requirements. Also, note that the positions at risk from COVID-19 make little use of green skills and require little training or experience. This further emphasizes that a 


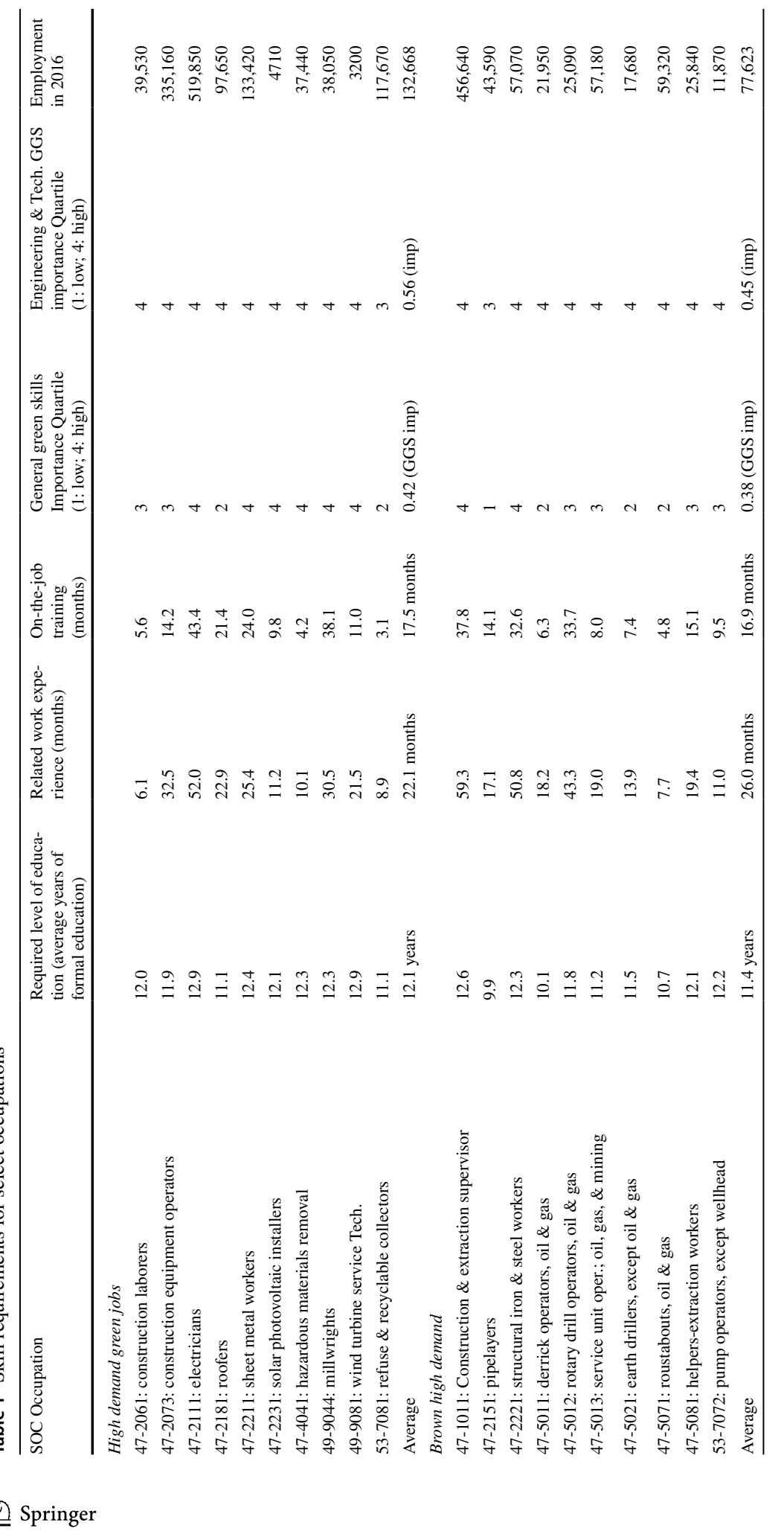




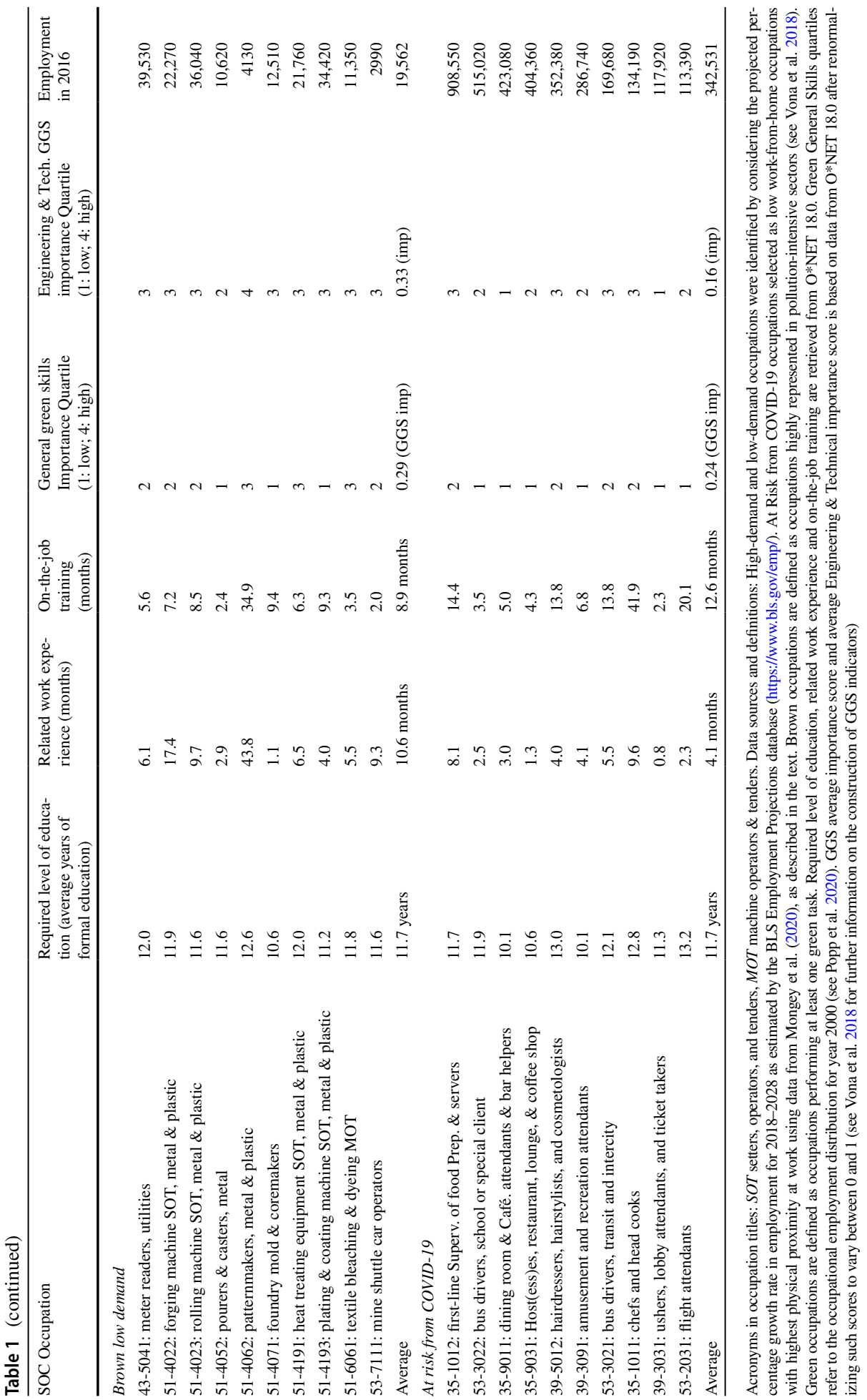




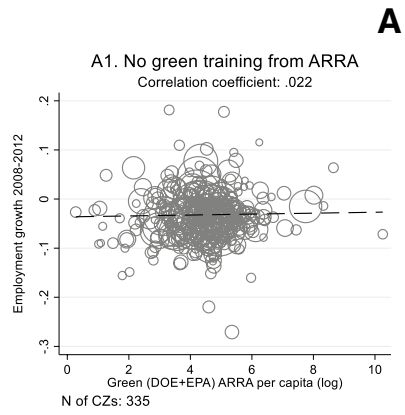

A Short-run employment growth (2008-2012)
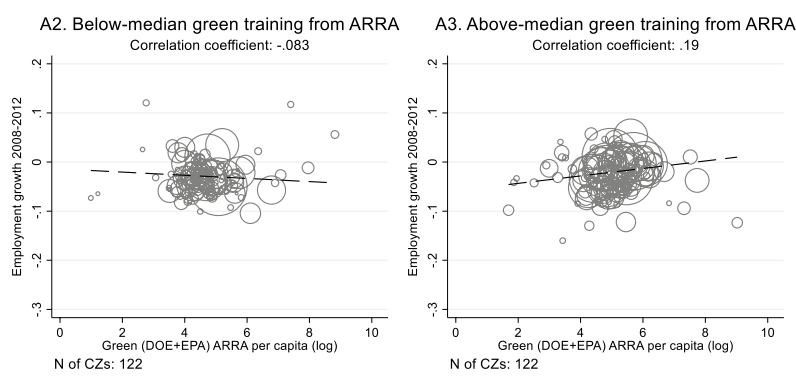

B
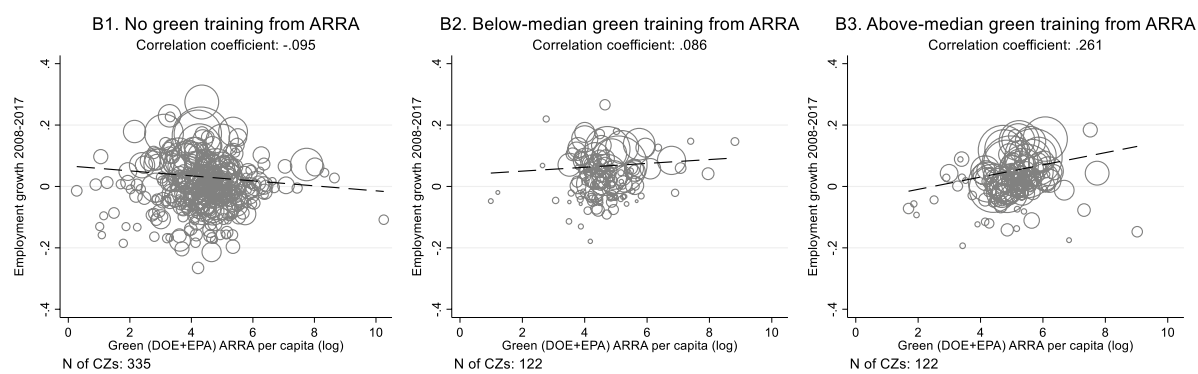

Fig. 1 Green ARRA and Employment Growth: The Role of Training. Notes: 579 Commuting Zones with population $>25 \mathrm{k}$. DOE+EPA ARRA spending refers to cumulative ARRA spending awarded by the Department of Energy and the Environment Protection Agency over 2009-2012 (Source: FedSpending.org). Employment growth: logarithmic difference in total employment (source: Quarterly Census on Employment and Wages, BLS) between 2012 and 2008 (panel A) and 2017-2008 (panel B). Size of circles is proportional to CZ's population in 2008. Correlation coefficients and linear interpolation are weighted with population in 2008. The median value of ARRA green training per capita for areas with positive funding is $\$ 2.6$

green stimulus will not, by itself, provide immediate assistance to those workers hurt most by COVID-19 lockdowns.

What about workers lacking the pre-requisite skills? We provide a preliminary answer to these questions based on the experience of the ARRA green package. The green package of ARRA included investments to retrain workers for green jobs. While small relative to the overall stimulus, DOE ARRA investments included \$228 million in job training, and the Department of Labor provided an additional \$496 million for four green job training programs. Together, these programs helped develop skills for energy efficiency retrofit and the renewable energy industry.

Figure 1 provides suggestive evidence that these training programs improved the effectiveness of green ARRA subsidies. The figure provides unconditional correlations between the log of green ARRA investments per capita and employment growth (panel A for short run (2008-2012), panel B for long run (2008-2018). We compute such correlations for areas which did not receive any ARRA funding for green training (charts A1 and B1, 335 commuting zones), areas that received below-median per-capita ARRA funding for green training (charts A2 and B2, 112 commuting zones) and areas that 
received above-median per-capita ARRA funding for green training (charts A3 and B3, 112 commuting zones). ${ }^{6}$

There are two main takeaways from this figure. First, the positive association between green ARRA spending and employment growth is present only in the 224 commuting zones (out of 559) receiving training investments. Such associations are much larger for areas above the median of green training spending. Second, these findings may explain why green stimulus funds took longer to create jobs, as the correlations between green ARRA and employment growth are greatest in the long-run. The correlation between green ARRA spending and employment growth is 0.261 for commuting zones receiving the largest amount of green training, 0.086 for commuting zones with some green training and negative for commuting zones with no green training.

These suggestive data, coupled with the findings of Popp et al. (2020) about the importance of green skills for the success of a green stimulus, imply a role for job training in the transition to a green economy. Recent studies suggest that climate policies may reduce jobs in specific sectors, particularly for lower skilled manual labor (Marin and Vona 2019; Yip 2018). The green jobs featured in Table 1 require over a year of on-the-job training, and workers from the energy sector who may be displaced in a greener economy have the prerequisite general skills for these new green jobs. That combination bodes well for the potential of job training to help energy sector workers displaced in the transition to a green economy. The larger gap in training requirement and green skills importance for lowdemand brown occupations and occupations at risk from COVID-19 lends further support on the role of training investments for the design of the future green stimulus packages. While there are examples of high-demand green jobs that require less training, such as construction laborers, it is still the case that those green occupations require more green skills than most low-demand brown jobs. Understanding which types of workers benefit from job training, and in particular whether job training can help those without green skills develop the skills needed for a green economy, requires data on training program participants and is left for future research.

The extent to which these preliminary results on the importance of on-the-job training applies to other countries depends on the institutional setup supporting investments in training by companies and workers (Hall and Soskice 2001). Labour economists suggest that stronger employment protection, the presence of unions and the quality of vocational schools all favour training investments. For instance, Acemoglu (2003) and Acemoglu and Pischke (1999) develop models where higher minimum wages or firing costs induce investments in training to enhance the productivity of unskilled workers. European countries, especially German speaking ones with their well-established systems of vocational and technical schools, appears well positioned to retrain workers for green jobs.

While we expect the skill set of European unskilled workers to better prepare them for the green transition than American unskilled workers, the lack of data for European countries does not allow us to compute the skill and training requirements similar to those of Table 1. However, indirect evidence using standardized test scores for workers in several countries show that not only is the distribution of key general skills (i.e., literacy and math)

\footnotetext{
$678.1 \%$ of the population lives in areas that received at least some funding for green training from ARRA. The average funding for green training is $\$ 2.4$ per capita, with substantial heterogeneity across areas: the average green training funding per capita for areas with positive but below-median funding $(48.9 \%$ of the population) was $\$ 1.2$, while people in areas above the median ( $22.9 \%$ of the population) received $\$ 11.7$ per capita on average.
} 
more dispersed in the US than in Europe, but also that the share of low skilled workers is higher in the US than in most European countries (Blau and Kahn 2005; Broecke et al. 2016). Moreover, since the technologies in use in Europe are similar to those in the US, we expect the skill gaps described in Table 1 to be relevant also for EU countries.

\section{Conclusions}

While green investments can play a role in a pandemic-related recovery, they should be seen as measures designed to assist in the inevitable transition to a greener economy, so that investments made now do not contribute to stranded energy assets likely to be obsolete in 10 years. Even without new climate policy initiatives, the COVID-19 crisis may trigger long-term structural transformations in the economy that are largely unpredictable now. On-going technological trends in the green and digital economy will not come to a halt, and may even be reinforced. For instance, might demand for fossil fuels fall as business travelers realize the potential of replacing face-to-face gatherings with video conferencing? Are communities dependent on shale oil production prepared for a world of low oil prices? With appropriate investments in job training, many of these workers have the skills needed to transition to greener jobs. Training support appears even more important for brown workers displaced in traditional manufacturing jobs in heavy industries (lowdemand brown occupations) for which the gap in green skills is larger. However, given the importance of green skill endowments for the success of green ARRA investments, whether job training will help workers overcome large skill gaps is a question that remains to be addressed in the empirical literature.

A more pressing need for pandemic-related assistance is helping workers in occupations most at risk from COVID-19. Here, green investments are less likely to help. It would be irresponsible for politicians to confuse the short-term and long-term needs and tell the voters that a green stimulus is going to magically bring back all the jobs, just as it would be irresponsible to argue that because we are in a crisis we can ignore problems of pollution and climate change. In addition to the skill mismatch between these displaced workers and green jobs, the longer lag time observed for green stimulus funds to take effect argues against using such funds to get workers back on their feet quickly. Instead, stimulus investments could help reduce the risks that workers in these jobs face, such as by providing technology and security equipment (e.g. masks, plexiglass barriers). Such investments should aim to both make it easier and safer to return to work, and to also give potential customers confidence in the safety of using these services.

For future research, richer data would enable more detailed study of green job training. For example, can job training help those without green skills develop the skills needed for a green economy, or is its effectiveness limited to those whose skills are close to what green jobs demand? Moreover, in Popp et al. (2020) we find that wage gains did not follow the increase in the demand of manual tasks in areas receiving higher green subsidies. Exploring whether this is due to the fact that the green jobs created are of low quality compared to similar jobs, or to the widespread deterioration of employment opportunities of the unskilled requires the use of longitudinal worker-level data and is left for future research.

Acknowledgements This project has been supported in part through the Smart Prosperity Institute Research Network and its Greening Growth Partnership, which is supported by a Social Sciences and Humanities Research Council of Canada Partnership Grant (No. 895-2017-1018), as well as by Environment and 
Climate Change Canada's Economics and Environmental Policy Research Network (EEPRN). This work was also supported by Horizon 2020 Framework Programme, project INNOPATHS [Grant number 730403].

\section{References}

Acemoglu D (2003) Cross-country inequality trends. Econ J 113(485):F121-F149

Acemoglu D, Pischke JS (1999) Beyond Becker: training in imperfect labour markets. Econ J 109(453):112-142

Agrawala SW, Dussaux D, Monti N (2020) What policies for greening the crisis response and economic recovery? Lessons learned from past green stimulus measures and implications for the COVID-19 crisis. OECD Environment Working Papers No. 164

Aldy JE (2013) Policy monitor-a preliminary assessment of the American Recovery and Reinvestment Act's clean energy package. Rev Environ Econ Policy 7(1):136-155

American Recovery and Reinvestment Act of 2009, Pub. L. 111-5, 123 Stat. 115, Section 3

Blau FD, Kahn LM (2005) Do cognitive test scores explain higher US wage inequality? Rev Econ Stat 87(1):184-193

Broecke S, Quintini G, Vandeweyer M (2016) Wage inequality and cognitive skills: re-opening the debate (No. w21965). National Bureau of Economic Research, Cambridge

Chodorow-Reich G (2019) Geographic cross-sectional fiscal spending multipliers: what have we learned? Am Econ J Econ Policy 11(2):1-34

Dupor B, McCrory PB (2018) A cup runneth over: fiscal policy spillovers from the 2009 Recovery Act. Econ J 128(611):1476-1508

Dupor B, Mehkari MS (2016) The 2009 Recovery Act: stimulus at the extensive and intensive labor margins. Eur Econ Rev 85:208-228

European Commission (2019) Communication from the Commission to the European Parliament, the European Council, the Council, the European Economic and Social Committee and the Committee of the Regions “The European Green Deal” COM(2019) 640, 11.12.2019

Garin A (2019) Putting America to work, where? Evidence on the effectiveness of infrastructure construction as a locally targeted employment policy. J Urban Econ 111:108-131

Gathmann C, Schönberg U (2010) How general is human capital? A task-based approach. J Labor Econ 28(1):1-50

Hafstead MA, Williams RC III (2018) Unemployment and environmental regulation in general equilibrium. J Public Econ 160:50-65

Hall PA, Soskice D (2001) Varieties of capitalism: the institutional foundations of comparative advantage. Oxford University Press, Oxford

Helm D (2020) The environmental impacts of the Coronoavirus. Environ Resour Econ 76:21-38

Kambourov G, Manovskii I (2009) Occupational specificity of human capital. Int Econ Rev 50(1):63-115

Marin G, Vona F (2019) Climate policies and skill-biased employment dynamics: evidence from EU countries. J Environ Econ Manag 98:102253

Mongey S, Pilossoph L, Weinberg A (2020) Which workers bear the burden of social distancing policies? National Bureau of Economic Research Working Paper \#27085

Montenovo L, Jiang X, Rojas FL, Schmutte IM, Simon KI, Weinberg BA, Wing C (2020) Determinants of disparities in Covid-19 job losses. National Bureau of Economic Research Working Paper \#27132

Popp D, Vona F, Marin G, Chen Z (2020) The employment impact of green fiscal push: evidence from the American Recovery Act. National Bureau of Economic Research Working Paper \#27321

Vona F (2019) Job losses and political acceptability of climate policies: why the 'job-killing' argument is so persistent and how to overturn it. Clim Policy 19(4):524-532

Vona F, Marin G, Consoli D, Popp D (2018) Environmental regulation and green skills: an empirical exploration. J Assoc Environ Resour Econ 5(4):713-753

Wilson DJ (2012) Fiscal spending jobs multipliers: evidence from the 2009 American Recovery and Reinvestment Act. Am Econ J Econ Policy 4(3):251-282

Yip CM (2018) On the labor market consequences of environmental taxes. J Environ Econ Manag $89: 136-152$

Publisher's Note Springer Nature remains neutral with regard to jurisdictional claims in published maps and institutional affiliations. 